DOI: https://doi.org/10.15688/jvolsu4.2017.1.13

UDC 327

Submitted: 14.06 .2016

LBC 66.4(Пол)

Accepted: 02.11.2016

\title{
THE KALININGRAD REGION IN EXPOSÉ OF MINISTERS OF FOREIGN AFFAIRS OF POLAND IN 2005-2016
}

\author{
Yana Antanovna Vorozheina \\ Immanuel Kant Baltic Federal University, Kaliningrad, Russian Federation
}

\begin{abstract}
Geographical and geopolitical proximity of the exclave Kaliningrad region and the Republic of Poland can be an essential basis for the formation of "Kaliningrad vector" of Warsaw's foreign policy (which might be a course separate from the general Poland's foreign policy towards Russian Federation). In this regard, the welltimed assessment of the features of the Poland's conceptual vision of neighborhood with exclave territory of Russia, as well as the nature and level of official Warsaw's interest in development of cooperation with the Kaliningrad region is extremely important. The evaluation of the impact of implementation of the Agreement between the Government of the Republic of Poland and the Government of the Russian Federation on the Rules of Local Border Traffic on significance of "Kaliningrad's focus" in the foreign policy strategy of the official Warsaw is also extremely important. In this context, it should be understood that thanks to this agreement, the Kaliningrad region has acquired an additional specificity in the context of Russian-Polish relations. This article is the attempt to determine the today's place and role of the Kaliningrad region in Poland's foreign policy strategy after joining the EU. The author reveals the period of updating theme of Poland's cooperation with the Kaliningrad region, as well as shows its nature and origins by analyzing the annual keynote addresses of the foreign ministers of Poland, which are concentrated on the basic provisions of the official foreign policy strategy of Warsaw.

Key words: Republic of Poland, foreign policy, foreign policy strategy, Kaliningrad region, cross-border cooperation, Russian-Polish relations.
\end{abstract}

УДК 327

ББК 66.4(Пол)
Дата поступления статьи: 14.06 .2016

Дата принятия статьи: 02.11.2016

\section{КАЛИНИНГРАДСКАЯ ОБЛАСТЬ В ЭКСПОЗЕ МИНИСТРОВ ИНОСТРАННЫХ ДЕЛ РЕСПУБЛИКИ ПОЛЬША В 2005-2016 ГОДАХ}

\section{Яна Антановна Ворожеина}

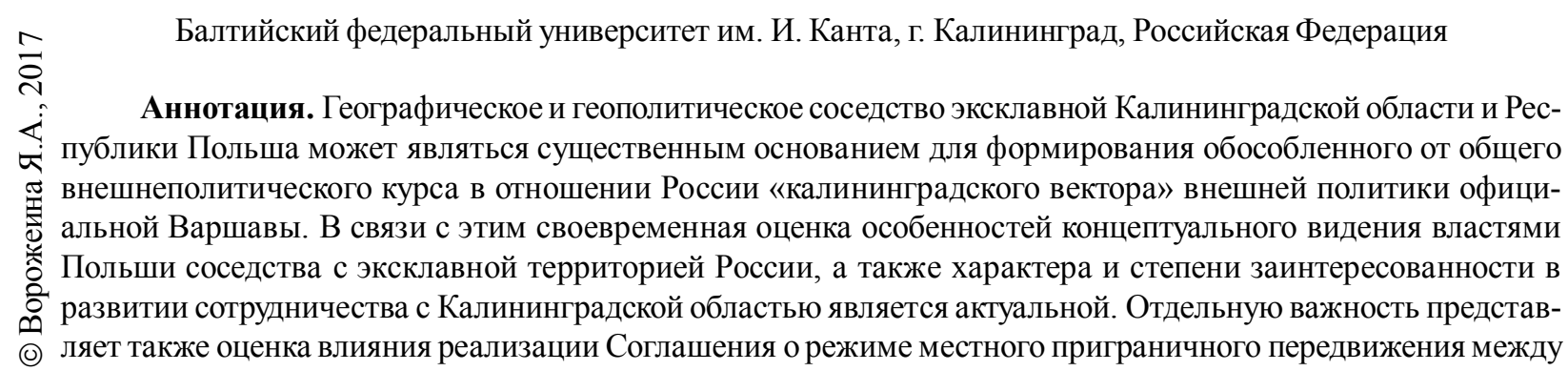


Россией и Польшей на значение темы сотрудничества с Калининградской областью во внешнеполитической стратегии польского правительства. В статье предпринимается попытка определения места и роли Калининградской области в приоритетах внешней политики Польши в период после ее вступления в ЕС. Автор, анализируя программные выступления (экспозе) министров иностранных дел Польши, базирующиеся на основных положениях внешнеполитической стратегии страны, выявляет период актуализации темы сотрудничества с Калининградской областью, а также раскрывает ее характер и истоки.

Ключевые слова: Республика Польша, внешняя политика, внешнеполитическая стратегия, Калининградская область, приграничное сотрудничество, российско-польские отношения.

Эксклавность Калининградской области определяет необходимость своевременной, многосторонней оценки внешнеполитических устремлений граничащих с регионом государств - членов Европейского союза и Североатлантического альянса - Польши и Литвы. Эти государства имеют общую границу с Российской Федерацией только в Калининградской области, что может способствовать формированию в указанных странах «калининградского вектора» внешней политики, обособленного от общего внешнеполитического курса в отношении России. В связи с этим естественную потребность вызывает осмысление роли и места Калининградской области во внешнеполитических стратегиях соседних государств. Такая оценка необходима как с точки зрения комплексного развития эксклавного региона, так и с точки зрения реализации внешнеполитических интересов Российской Федерации в Юго-Восточной Прибалтике. А.П. Клемешев подчеркивает, что «на примере эксклавной территории мы имеем уникальный случай становления регионально-государственно-международной социально-экономической системы жизнедеятельности человека и общества в условиях, когда для региона значимым становится комплекс проблем глобального развития» [1, с. 36].

В сфере экономического сотрудничества с Калининградской областью как ранее, так и на текущий момент Польша существенно опережает Литву [25, s. 280-281]. По данным за 2014 г. товарооборот Польши с Калининградской областью составил почти 1 млрд долл. США, в то время как товарооборот Литовской Республики с российским эксклавом около 500 млн долл. США, в 2015 г. эта цифра снизилась до 232,5 млн долл. США [5, s. 15; 20]. Еще более значительно Польша опережает Литву в сфере трансграничного сотрудничества с Калининградской областью.
Наша задача заключается в определении места и роли Калининградской области во внешнеполитической стратегии Республики Польша. Прежде всего внимание сосредоточено на программных выступлениях министров иностранных дел Польши, так называемых экспозе. Данный тип документов в концентрированном виде представляет основные положения внешнеполитической стратегии официальной Варшавы, ежегодно претерпевающие корректировки в соответствии с актуальным внутри- и внешнеполитическим контекстом.

Целесообразно рассмотреть экспозе, представленные в относительно не отдаленной ретроспективе - с момента вступления Польши в Европейский союз 1 мая 2004 г., так как обретение Республикой членства в ЕС требовало переориентации внешнеполитических приоритетов в соответствии с новыми условиями. Безусловно, это касалось внешнеполитического курса в отношении соседних государств - не членов ЕС [22; 23; 24]. Кроме того, после включения Республики в НАТО вступление в ЕС определило обретение Калининградской областью качественно иных геополитических условий, что, в свою очередь, могло повлиять на внешнеполитический курс Польши в отношении российского эксклава.

Первое после вступления Польши в Европейский союз экспозе было оглашено в 2005 г. беспартийным министром иностранных дел Адамом Ротфельдом, который занимал этот пост в январе - октябре 2005 г. в составе коалиционного левоцентристского правительства парламентского меньшинства. В экспозе А. Ротфельда вопросам польско-российских отношений, их развитию было уделено заметное внимание. Однако, несмотря на это, упоминания о Калининградской области в программном выступлении отсутствовали [7, s. 303-321]. 
В экспозе министров иностранных дел Стефана Меллера (министр в октябре 2005 мае 2006 г. в составе правого кабинета, беспартийный), Анны Фотыги (министр в мае 2006 - ноябре 2007 г. в составе правого кабинета Я. Качиньского, член партии «Право и справедливость») и Радослава Сикорского (министр в ноябре 2007 - сентябре 2014 г. в составе левоцентристского кабинета Д. Туска, член партии «Гражданская платформа»), представленных с 2006 по 2010 г., Калининградская область среди внешнеполитических приоритетов также не фигурировала, несмотря на то, что Российской Федерации, развитию польско-российских отношений и посредничеству Польши при выстраивании отношений на линии Россия - ЕС было уделено существенное внимание [7, s. 321-438]. В этот период политический истеблишмент Польши активно пытался участвовать в конструировании «восточной политики» ЕС, преследуя в первую очередь цели национальной внешней политики. Для Варшавы приоритетами «восточной политики» являются: продвижение демократии; торгово-экономическое сотрудничество на основе селективного (даже ситуационного) подхода к конкретным государствам; исключение военной угрозы с Востока; продолжение политики побуждения к интеграции (по образцу той, что проводилась ЕС в отношении стран Центрально-Восточной Европы в начале 1990-х гг.) [3, с. 23]. Именно ситуационный подход превалировал в определении роли российского эксклава во внешнеполитической стратегии Польши.

Первое упоминание о Калининградской области после продолжительного перерыва в экспозе за рассматриваемый период обнаружено в 2011 году. Объяснить появление «калининградской темы» в выступлении главы внешнеполитического ведомства можно тем, что именно тогда было заключено Соглашение между Правительством Республики Польша и Правительством Российской Федерации о порядке местного приграничного передвижения (далее - МПП), подписанное 14 декабря 2011 г. [2; 6].

В соответствии с Регламентом № 1931/ 2006 Европейского парламента и Совета от 20 декабря 2006 г., устанавливающим предписания, касающиеся местного приграничного пе- редвижения на внешних сухопутных границах государств-членов, и изменяющим положения Шенгенской конвенции, режим МПП может распространяться только на 30 км от границы, и лишь в некоторых случаях на 50 км [19].

Соглашение, заключенное Россией и Польшей, выходит за рамки условий Регламента. С польской стороны зона МПП распространяется почти на 100 км от границы в пределах некоторых повятов Поморского и Варминьско-Мазурского воеводств [2], со стороны Российской Федерации режим охватывает всю Калининградскую область, практически соразмерную польской зоне МПП. Европейской комиссией для Калининградской области было сделано исключение, являющееся на данный момент единственным в своем роде. Безусловно, проявленная инициатива по расширению зоны МПП, прежде всего со стороны Польши, подразумевала перспективы экономической выгоды, развития польских приграничных территорий. Однако в пояснении министерства иностранных дел Польши в отношении необходимости увеличения протяженности зоны МПП отмечалось, что именно эксклавность Калининградской области требует правового решения, выходящего за рамки Регламента ЕС № 1931/2006 [16].

Вместе с тем подписание Соглашения о МПП и его успешная реализация не являются ни подтверждением существования концептуально сформированного, последовательного внешнеполитического курса Польши в отношении Калининградской области, ни отражением актуализации вопроса развития сотрудничества с эксклавным регионом в приоритетах внешней политики официальной Варшавы. Можно согласиться с выводом М. Хелминака и В. Котовича о том, что «реализация соглашения о малом пограничном движении может улучшить приграничное взаимодействие, однако оно существенно не изменит роль Калининградской области во внешней политике Польши» [4, с. 79].

Менее чем через год после подписания Соглашения о МПП правительство Польши сформировало приоритеты внешней политики на 2012-2016 гг., в которых отмечалась важность поддержания прагматичных, добрососедских отношений с Россией, однако роли Калининградской области ни в этом воп- 
росе в частности, ни во внешнеполитических приоритетах в целом внимания уделено не было [17].

В своем выступлении министр Р. Сикорский отметил: «Нам удалось договориться о Соглашении о местном приграничном передвижении, которое создает перспективы открытости Крулевецкой области для Европы» [10]. Пребывая в должности министра иностранных дел, Р. Сикорский, высказываясь о Калининградской области, использовал экзоним «Крулевецкая область» или «Крулевецкий округ». Решением Комиссии стандартизации географических названий за границей Республики Польша в 2005 г. употребление названия «Крулевец» (польское наименование города Кенигсберга, который во времена короля Казимира IV около года принадлежал Польше) как экзонима признано допустимым, но не рекомендуемым. Р. Сикорский объяснял употребление экзонима «Крулевец» происхождением названия города Калининград. В одном из интервью министр заявил: «...напоминаю, что товарищ Калинин был сталинским преступником, среди прочих подписавшим приказ о расстреле польских офицеров в Катыни, Харькове и Медном. Мы не считаем, что было бы правильным способствовать увековечиванию памяти об этом человеке» [18].

Наиболее заметное место Калининградская область заняла в экспозе министра Р. Сикорского за 2012 [11], 2013 и 2014 годы. Калининградская область неакцентированно (однократно в каждом документе), но коннотативно значимо упоминалась в контексте позитивных эффектов введения режима МПП. Так, в экспозе 2013 г. отмечалось: «Мы заинтересованы в сотрудничестве между Польшей и Россией, особенно между регионами и локальными обществами. <..> Мы видим, что сдает экзамен Соглашение о местном приграничном передвижении, которое позволяет жителям северной Польши и Крулевецкой области познакомиться друг с другом. Большая открытость границ - это также измеримая экономическая выгода» [12].

В экспозе Р. Сикорского в 2014 г. министр вновь подчеркнул социальную и экономическую успешность реализации Соглашения о МПП, которое получило неофициальное название «проект Восточной Пруссии» [13].
Отдельный интерес представляет информация о задачах польской внешней политики на 2014-2015 гг., озвученная министром иностранных дел Польши Гжегожем Схетыной (министр в сентябре 2014 - ноябре 2015 г. в составе центристского правительства, член партии «Гражданская платформа»). В данном документе Калининградская область однократно упоминалась в контексте оценки состояния польско-российских отношений и позитивных эффектов введения режима МПП. «Критическая оценка [Польшей] российской политики не изменяет того факта, что мы остаемся соседями и экономическими партнерами. Считаем, что польско-российские отношения могут быть хорошими. В этой мере мы имеем позитивный пример хотя бы местного приграничного передвижения с Калининградской областью, которое приносит измеримые экономические и социальные выгоды обеим нашим странам. В отношениях с Российской Федерацией мы будем стремиться к сохранению сотрудничества там, где это возможно» [14]. Нетрудно заметить, что сотрудничество с Калининградской областью рассматривается исключительно в положительном ключе, выступает в качестве успешного примера польско-российского взаимодействия в целом. Однако спустя несколько месяцев в экспозе Г. Схетыны за 2015 г. тема Калининградской области не нашла отражения [8].

В ноябре 2015 г. в результате победы на парламентских выборах правительство Польши сформировала правая консервативная партия «Право и справедливость», выступившая в 2012 г. против ратификации соглашения о режиме МПП с Калининградской областью [21]. Первая министерская декларация Витольда Ващчиковского была представлена в январе 2016 года. Несмотря на то что теме польско-российских отношений в экспозе уделено особое внимание, упоминания о Калининградской области в приоритетах внешней политики Польши на ближайший год отсутствовали [9].

Результаты проведенного анализа не позволяют говорить о существовании концептуально сформированного «калининградского вектора» внешнеполитической стратегии официальной Варшавы, обособленного от общего курса в отношении России. В период с мо- 
мента вступления Польши в НАТО и Европейский союз Калининградская область не выделялась в экспозе польских министров иностранных дел ни в качестве приоритетного региона для внешней политики страны в целом, ни в качестве особо важного региона для развития польско-российских отношений в частности.

Однако стоит подчеркнуть, что подписание и реализация Соглашения о порядке местного приграничного передвижения между Россией и Польшей способствовала актуализации во внешнеполитической повестке официальной Варшавы (в 2011-2014 гг.) темы сотрудничества с Калининградской областью. Примечательно, что в программных выступлениях министров иностранных дел Польши в этот период действующий режим МПП рассматривался не только с точки зрения образца успешного приграничного сотрудничества, экономических и социальных выгод, но также с точки зрения примера позитивного опыта польско-российского взаимодействия в условиях охлаждения отношений между Россией и Западом. Немаловажным является и то, что, несмотря на дискретный характер актуализации калининградской темы в рассмотренных программных выступлениях глав внешнеполитического ведомства Польши, все упоминания о Калининградской области имели исключительно положительное коннотативное значение. Кроме того, ни в одном из проанализированных документов не подвергалась сомнению целесообразность трансграничного сотрудничества северо-восточных воеводств с Калининградской областью в рамках режима МПП. Однако в настоящее время с приходом к власти в Польше правой консервативной партии «Право и справедливость» ситуация кардинальным образом изменилась с 4 июля 2016 г. режим местного приграничного передвижения между Польшей и Россией по инициативе польского министерства внутренних дел был приостановлен на неопределенный срок. Министерство внутренних дел Польши аргументировало приостановку режима МПП «причинами, связанными с вопросами безопасности» [15], что может оказать негативное влияние на актуализацию темы сотрудничества с Калининградской областью в будущем.

\section{СПИСОК ЛИТЕРАТУРЫ}

1. Клемешев, А. П. Эксклавность как фактор развития Калининградской области / А. П. Клемешев // Вестник Балтийского федерального университета им. И. Канта. Серия: Гуманитарные и общественные науки. - 2005. - № 3. - С. 34-41.

2. Соглашение между правительством Российской Федерации и правительством Республики Польша о порядке местного приграничного передвижения. - Электрон. текстовые дан. - Режим доступа: https://www.msz.gov.pl/resource/d1b6ee1e2e56-499e-961c-60802116fafe (дата обращения: 05.06.2016). - Загл. с экрана.

3. Тарасов, И. Н. Конструирование новой «Восточной политики» Европейского союза / И. Н. Тарасов // Полития. Анализ. Хроника. Прогноз. 2008. - № 2. - С. 18-30.

4. Хелминак, М. Внешняя политика Польши и Калининградской области в период 1989-2012 гг. / М. Хелминак, В. Котович // Балтийский регион. 2012. - № 4 (14). - C. 72-81.

5. Batyk, I. Wpływ sankcji gospodarczych na strukturę polskiego eksportu produktów rolnospożywczych do Rosji. - Electronic text data. - Mode of access: http://www.wneiz.pl/nauka_wneiz/sip/sip412015/SiP-41-t1-235.pdf(date of access: 05.06.2016).Title from screen.

6. Dudzińska, K. Mały ruch graniczny między obwodem kaliningradzkim a Polską - wyzwania, szanse i zagrożenia / K. Dudzińska, A. M. Dyner // PISM Policy Paper. - 2013. - № 29 (77).

7. Expose Ministrów Spraw Zagranicznych 1990-2011 / red. Paweł Ceranka ; Ministerstwo Spraw Zagranicznych ; Biuro Archiwum i Zarządzania Informacją. - Warszawa : MSZ. BAiZI, 2011.

8. Informacja Ministra Spraw Zagranicznych o zadaniach polskiej polityki zagranicznej w 2015 r. Electronic text data. - Mode of access: https://www. msz.gov.pl/resource/92c4a18e-bef7-437e-94af19a5b6df414a:JCR (date of access: 05.06.2016). - Title from screen.

9. Informacja Ministra Spraw Zagranicznych o zadaniach polskiej polityki zagranicznej w 2016 roku. Electronic text data. - Mode of access: https://www. $\mathrm{msz} . g o v . \mathrm{pl} / \mathrm{pl} / \mathrm{p} / \mathrm{msz}$ _pl/ministerstwo/minister/ wystapienia/informacja_ministra_spraw zagranicznych_o_zadaniach_polskiej_polityki_ zagranicznej_w_2016_roku (date of access: 05.06.2016). - Title from screen.

10. Informacja Ministra Spraw Zagranicznych Pana Radosława Sikorskiego dotycząca zadań polskiej polityki zagranicznej w 2011 roku. - Electronic text data. - Mode of access: http://www.msz.gov.pl/ resource/6fd9a0c0-79ef-4eac-82ef-5fbc4202948e:JCR (date of access: 05.06.2016). - Title from screen. 
11. Informacja Ministra Spraw Zagranicznych Pana Radosława Sikorskiego dotycząca zadań polskiej polityki zagranicznej w 2012 roku. - Electronic text data. - Mode of access: http://www.msz.gov.pl/ resource/bbcf833e-0136-46d0-8551-424cf7304535:JCR (date of access: 05.06.2016). - Title from screen.

12. Informacja Ministra Spraw Zagranicznych Pana Radosława Sikorskiego dotycząca zadań polskiej polityki zagranicznej w 2013 roku. - Electronic text data. - Mode of access: http://www.msz.gov.pl/ resource/43569e19-908b-4695-9520-19d34407af2a:JCR (date of access: 05.06.2016). - Title from screen.

13. Informacja Ministra Spraw Zagranicznych Pana Radosława Sikorskiego dotycząca zadań polskiej polityki zagranicznej w 2014 roku. - Electronic text data. - Mode of access: http://www.msz.gov.pl/pl/p/ $\mathrm{msz}$ pl/ministerstwo/historia/ministrowie_sz_1918_ 2014/wystapienia_radoslawa_sikorskiego/informacja ministra_spraw_zagranicznych_nt_polityki_polonijnej (date of access: 05.06.2016). - Title from screen.

14. Informacja Rady Ministrów o zadaniach polskiej polityki zagranicznej w latach 2014-2015.Electronic text data. - Mode of access: https://www. msz.gov.p1/resource/6ab04ba 1-6034-452a-bbec0a13d5dc7379:JCR (date of access: 05.06.2016). - Title from screen.

15. Mały ruch graniczny z Rosją nie zostanie przywrócony. - Electronic text data. - Mode of access: http://niezalezna.pl/84173-maly-ruch-graniczny-z-rosjanie-zostanie-przywrocony-wzgledy-bezpieczenstwa (date of access: 05.06.2016). - Title from screen.

16. Odpowiedź sekretarza stanu w Ministerstwie Spraw Zagranicznych na interpelację nr $21819 \mathrm{w}$ sprawie skutków objęcia całego terytorium obwodu królewieckiego porozumieniem o małym ruchu granicznym. - Electronic text data. - Mode of access: http://orka2.sejm.gov.pl/IZ6.nsf/main/4D8F5EF0 (date of access: 05.06.2016). - Title from screen.

17. Priorytety Polskiej polityki zagranicznej 2012 2016. - Warszawa : Ministerstwo Spraw Zagranicznych, 2012.

18. Radosław Sikorski walczy z «Kaliningradem». Electronic text data. - Mode of access: http://wiadomosci. gazeta.pl/wiadomosci/1,114873,9633232,Radoslaw_ Sikorski_walczy_z_Kaliningradem_.html (date of access: 05.06.2016). - Title from screen.

19. Rozporządzenie(WE) nr 1931/2006 Parlamentu Europejskiego i Rady z dnia 20 grudnia 2006 r. ustanawiające przepisy dotyczace małego ruchu granicznego na zewnętrznych granicach lądowych państw członkowskich i zmieniające postanowienia Konwencji z Schengen. - Electronic text data. - Mode of access: http://udsc.gov.pl/wp-content/uploads/2014/ 12/z.pdf(date of access: 05.06.2016). - Title from screen.

20. Rusijos administracinių teritorijų importas iš Lietuvos (struktūrinè analizè). - Electronic text data. -
Mode of access: http://old2.verslilietuva.lt/uploads/ file/2015.07.15_Rusijos_regionu_importas_is_ Lietuvos_strukturine_analize_F.pdf (date of access: 05.06.2016). - Title from screen.

21. Rządowy projekt ustawy o ratyfikacji Umowy między Rządem Rzeczypospolitej Polskiej a Rządem Federacji Rosyjskiej o zasadach małego ruchu granicznego, podpisanej w Moskwie dnia 14 grudnia 2011r. - Electronic text data. - Mode of access: http:// www.sejm.gov.pl/sejm7.nsf/PrzebiegProc.xsp?nr=199 (date of access: 05.06.2016). - Title from screen.

22. Stemplowski, R. Wprowadzenie do analizy polityki zagranicznej RP/R. Stemplowski. - Warszawa : PISM, 2006.

23. Szeptycki, A. Nowa odsłona polskiego mesjanizmu na Wschodzie? / A. Szeptycki // Polityka zagraniczna Polski po wstapieniu do NATO i Unii Europejskiej. Problemy tożsamości i adaptacji / red. Bieleń S. - Warszawa : DIFIN, 2010.

24. Uwarunkowania i kierunki polskiej polityki zagranicznej w pierwszej dekadzie XXI wieku / pod red. M. S. Wolański. - Wrocław : Arboretum : Instytut Studiów Międzynarodowych Wydziału Nauk Społecznych Uniwersytetu Wrocławskiego, 2004.

25. Wybrane problemy gospodarczej współpracy transgranicznej z Obwodem Kaliningradzkim Federacji Rosyjskiej// Relacje nowych krajów Unii europejskiej z Federacją Rosyjską w aspekcie politycznym, ekonomicznym, kulturowym i społecznym. - Białystok : Wydawnictwo Wyższej Szkoły Finansów i Zarządzania, 2008. - S. 277-289.

\section{REFERENCES}

1. Klemeshev A.P. Eksklavnost kak faktor razvitiya Kaliningradskoy oblasti [Exclavelity as a Factor of the Kaliningrad Region Development]. Vestnik Baltiyskogo federalnogo universiteta im. I. Kanta. Seriya: Gumanitarnye i obshchestvennye nauki, 2005, no. 3, pp. 34-41.

2. Soglashenie mezhdu pravitelstvom Rossiyskoy Federatsii i pravitelstvom Respubliki Polsha o poryadke mestnogo prigranichnogo peredvizheniya [The Agreement between the Government of the Republic of Poland and the Government of the Russian Federation on the Rules of Local Border Traffic]. Available at: https:// www.msz.gov.pl/resource/d1b6ee1e-2e56-499e-961c60802116fafe. (accessed June 5, 2016).

3. Tarasov I.N. Konstruirovanie novoy «Vostochnoy politiki» Evropeyskogo soyuza [Construction of the New "Eastern Policy" of the European Union]. Politiya. Analiz. Khronika. Prognoz, 2008, no. 2, pp. 18-30. 
4. Khelminak M., Kotovich V. Vneshnyaya politika Polshi i Kaliningradskoy oblasti v period 19892012 gg. [Foreign Policy of Poland and the Kaliningrad Region in 1989-2012]. Baltiyskiy region, 2012, no. 4 (14), pp. 72-81.

5. Batyk I. Wptyw sankcji gospodarczych na strukture polskiego eksportu produktów rolnospożywczych do Rosji. Available at: http://www. wneiz.pl/nauka wneiz/sip/sip41-2015/SiP-41-t1-235. pdf. (accessed June 5, 2016).

6. Dudzińska K. Mały ruch graniczny między obwodem kaliningradzkim a Polską - wyzwania, szanse i zagrożenia. PISM Policy Paper, 2013, no. 29 (77).

7. Ceranka P., ed. Expose Ministrów Spraw Zagranicznych 1990-2011. Warszawa, MSZ. BAiZI, 2011.

8. Informacja Ministra Spraw Zagranicznycho zadaniach polskiej polityki zagranicznej w $2015 \mathrm{r}$. Available at: https://www.msz.gov.pl/resource/ 92c4a18e-bef7-437e-94af-19a5b6df414a:JCR. (accessed June 5, 2016).

9. Informacja Ministra Spraw Zagranicznycho zadaniach polskiej polityki zagranicznej w 2016 roku. Available at: https://www.msz.gov.pl/pl/p/msz $\mathrm{pl} /$ ministerstwo/minister/wystapienia/informacja ministra_spraw_zagranicznych_o_zadaniach_polskiej_ polityki_zagranicznej_w_2016_roku. (accessed June 5, 2016).

10. Informacja Ministra Spraw Zagranicznych Pana Radosiawa Sikorskiego dotyczooca zadac polskiej polityki zagranicznej w 2011 roku. Available at: http://www.msz.gov.pl/resource/6fd9a0c0-79ef4eac-82ef-5fbc4202948e:JCR. (accessed June 5, 2016).

11. Informacja Ministra Spraw Zagranicznych Pana Radosława Sikorskiego dotyczaca zadań polskiej polityki zagranicznej w 2011 roku. Available at: http://www.msz.gov.pl/resource/bbcf833e-013646d0-8551-424cf7304535:JCR. (accessed June 5, 2016).

12. Informacja Ministra Spraw Zagranicznych Pana Radostawa Sikorskiego dotyczqca zadań polskiej polityki zagranicznej w 2013 roku. Available at: http://www.msz.gov.pl/resource/43569e19-908b4695-9520-19d34407af2a:JCR. (accessed June 5, 2016).

13. Informacja Ministra Spraw Zagranicznych Pana Radosława Sikorskiego dotyczaca zadań polskiej polityki zagranicznej w 2014 roku. Available at: http://www.msz.gov.pl/pl/p/msz_pl/ministerstwo/ historia/ministrowie_sz_1918_2014/wystapienia_ radoslawa_sikorskiego/informacja_ministra_spraw_ zagranicznych_nt_polityki_polonijnej. (accessed June 5, 2016).

14. Informacja Rady Ministrów o zadaniach polskiej polityki zagranicznej w latach 2014-2015. Available at: https://www.msz.gov.pl/resource/6ab04ba16034-452a-bbec-0a13d5dc7379:JCR. (accessed June 5, 2016).
15. Maty ruch graniczny z Rosja nie zostanie przywrócony. Available at: http://niezalezna.pl/84173maly-ruch-graniczny-z-rosja-nie-zostanieprzywrocony-wzgledy-bezpieczenstwa. (accessed June 5, 2016).

16. Odpowiedź sekretarza stanu w Ministerstwie Spraw Zagranicznych na interpelacje nr 21819 w sprawie skutków objęcia catego terytorium obwodu królewieckiego porozumieniem o matym ruchu granicznym. Available at: http://orka2.sejm.gov.pl/ IZ6.nsf/main/4D8F5EF0. (accessed June 5, 2016).

17. Priorytety Polskiej polityki zagranicznej 2012-2016. Warszawa, Ministerstwo Spraw Zagranicznych, 2012.

18. Radostaw Sikorski walczy $z$ «Kaliningradem». Available at: http://wiadomosci.gazeta.pl/wiadomosci/ 1,114873,9633232,Radoslaw_Sikorski_walczy_z_ Kaliningradem_html.(accessed June 5, 2016).

19. Rozporzadzenie (WE) $n r$ 1931/2006 Parlamentu Europejskiego i Rady z dnia 20 grudnia $2006 r$. ustanawiajace przepisy dotyczqce matego ruchu granicznego na zewnętrznych granicach ladowych panstw członkowskich i zmieniajace postanowienia Konwencji z Schengen. Available at: http://udsc.gov.pl/wp-content/uploads/2014/12/z.pdf. (accessed June 5, 2016).

20. Rusijos administraciniu teritoriju importas iš Lietuvos (struktürine analizè). Available at: http:// old2.verslilietuva.1t/uploads/file/2015.07.15_ Rusijos_regionu_importas_is_Lietuvos_strukturine analize_F.pdf. (accessed June $\overline{5}, 2016$ ).

21. Rzadowy projekt ustawy o ratyfikacji Umowy między Rzqdem Rzeczypospolitej Polskiej a Rzqdem Federacji Rosyjskiej o zasadach matego ruchu granicznego, podpisanej w Moskwie dnia 14 grudnia 2011 r. Available at: http://www.sejm.gov.pl/sejm7.nsf/ PrzebiegProc.xsp?nr=199. (accessed June 5, 2016).

22. Stemplowski R. Wprowadzenie do analizy polityki zagranicznej RP. Warszawa, PISM, 2006.

23. Szeptycki A. Nowa odsłona polskiego mesjanizmu na Wschodzie? Bieleń S., ed. Polityka zagraniczna Polski po wstapieniu do NATO i Unii Europejskiej. Problemy tożsamości i adaptacji. Warszawa, DIFIN, 2010.

24. Wolański M.S., ed. Uwarunkowania $i$ kierunki polskiej polityki zagranicznej w pierwszej dekadzie XXI wieku. Wrocław, Arboretum: Instytut Studiów Studiów Międzynarodowych Wydziału Nauk Społecznych Uniwersytetu Wrocławskiego, 2004.

25. Wybrane problemy gospodarczej współpracy transgranicznej z Obwodem Kaliningradzkim Federacji Rosyjskiej. Relacje nowych krajów Unii europejskiej $z$ Federacja Rosyjskq w aspekcie politycznym, ekonomicznym, kulturowym i społecznym. Białystok, Wydawnictwo Wyższej Szkoły Finansów i Zarządzania, 2008, pp. 277-289. 


\section{Information about the Author}

Yana A. Vorozheina, Postgraduate Student, Institute for the Humanities, Immanuel Kant Baltic Federal University, Chernyshevskogo St., 56, 236022 Kaliningrad, Russian Federation, j.worozheina@gmail.com, http://orcid.org/0000-0003-4777-2051.

\section{Информация об авторе}

Яна Антановна Ворожеина, аспирант Института гуманитарных наук, Балтийский федеральный университет им. И. Канта, ул. Чернышевского, 56, 236022 г. Калининград, Российская Федерация, j.worozheina@gmail.com, http://orcid.org/0000-0003-4777-2051. 